\title{
EL PROYECTO DE PLAZA DE TOROS DE PICASSO Y SU RELACIÓN CON LA ARQUITECTURA DE MASAS
}

Data recepción: 2013/12/20

Data aceptación: 2014/04/29

Contacto autora: rperales@unex.es
Rosa Perales Piqueres

Universidad de Extremadura

\section{RESUMEN}

Estudio sobre el proyecto realizado por Pablo Picasso, Antonio Bonet y Luis Miguel Dominguín, para la realización de una plaza de toros desde el concepto de arquitectura contemporánea de masas. A partir de las anotaciones del artista, sobre su visión de la fiesta y el toro y su relación con los personajes, se investigan los bocetos y tratamientos espaciales que plantean aspectos comunes entre las teorías de Le Corbusier y la visión de arte total de Picasso. Antonio Bonet, discípulo del arquitecto suizo, será quien transmita las enseñanzas del maestro en proyectos iberoamericanos y españoles, aplicándolos posteriormente a la hora de de diseñar una arquitectura de coso taurino, basada en materiales, estructuras y circulación de público con una visión pionera y novedosa en la arquitectura española.

Palabras clave: Arquitectura del siglo XX, Plaza de toros, Picasso, Arquitecto, Antonio Bonet, Le Corbusier

\section{ABSTRACT}

A study of the project undertaken by Pablo Picasso, Antonio Bonet and Luis Miguel Dominguín for the construction of a bullring in accordance with the concept of contemporary architecture for the masses. Using the artist's notes on his vision of bullfighting and the bull and its relationship with the characters, research is conducted into sketches and spatial treatments that reveal commonalities between the theories of Le Corbusier and Picasso's vision of total art. A disciple of the Swiss architect, Bonet conveyed the master's teachings in Latin American and Spanish projects, and later applied them in designing bullring architecture based on materials, structures and people flows with a vision that was pioneering and innovative for Spanish architecture.

Keywords: twentieth-century architecture, bullring, Picasso, architect, Antonio Bonet, Le Corbusier

\section{Introducción. Objetivos y método.}

En la última etapa de su vida, Pablo Picasso se planteó la posibilidad de construir una plaza de toros, inicialmente privada, en su residencia de Vauvenargues. Lo que iba a ser en un principio una pequeña plaza, similar a las de las tientas en las fincas ganaderas, se convertirá en un proyecto de grandes dimensiones, cuyo resultado es todo un alarde de arquitectura moderna. Este proyecto de Pablo Picasso nos permite analizar su interés por la construcción de una plaza de toros y decorarla con obra cerámica. La iniciativa es el producto de las ideas de tres personajes, el arquitecto Antonio Bonet Castellana, el torero
Luis Miguel Dominguín y Picasso, el impulsor y promotor del mismo.

Hasta el momento, apenas se han realizado estudios sobre Picasso y su relación con la arquitectura. Tan solo contamos con la escasa información que nos proporciona el arquitecto Antonio Bonet Castellana en su biografía, información basada en una serie de datos sobre el encuentro del artista con el arquitecto para diseñar un anteproyecto en el año 1960, pero sin ningún tipo de análisis ni conclusiones artísticas. De ahí la necesidad de llevar a cabo un estudio sobre el pensamiento de Picasso y el hecho arquitectónico en sí. 
Nuestro trabajo consiste en el estudio y análisis de los documentos existentes sobre el anteproyecto. Para ello hemos tenido en cuenta, básicamente, los referentes ideológicos de la arquitectura del gran maestro Le Corbusier a través de la obra de su discípulo Antonio Bonet y el imaginario taurino de Picasso.

El desarrollo del trabajo consiste en mostrar, a través de varios epígrafes, aspectos diferenciados con respecto a los personajes que intervienen. En primer lugar, planteamos un análisis sobre el pensamiento de Picasso con respecto al arte de la tauromaquia como alegoría vital, necesario para entender mejor el porqué del proyecto; en segundo lugar, estudiamos los modelos y referentes arquitectónicos de Le Corbusier, que van a ser los antecedentes que explican el diseño final de la obra; en tercer lugar, analizamos en profundidad la obra de Antonio Bonet, arquitecto autor del proyecto que trabaja en el ámbito de la arquitectura de masas; en cuarto y último lugar, intentamos poner en relación el pensamiento del artista, la teoría arquitectónica de la época y la obra de Antonio Bonet a través del análisis del proyecto.

\section{El sueño de Picasso.}

De todos es conocida la famosa afición a la tauromaquia de Picasso y como se convierte, en numerosas ocasiones, en el motivo principal de su arte. Su obsesión por el tema es también la consecuencia de su reflexión sobre la vida y la muerte, la naturaleza animal y la humana y su sentido de la existencia.

La última etapa del artista nos la presentan sus biógrafos como la de un hombre octogenario, obsesionado con la soledad y la muerte, y, por ende, aficionado al mundo de los toros, al que acudirá regularmente en las plazas de Nimes y Arlés ${ }^{1}$. La escritora y crítica de arte Hèlene Parmelin, en su libro "Picasso en el ruedo"2, hace una reflexión sobre la relación del autor con el mundo de los toros, presente en gran parte de sus manifestaciones formales y estéticas: pintura, grabado, escultura o cerámica. Parmelín afirma que sus obsesiones por la corrida las manifestaba a través de sueños, en concreto de uno, que se repetía insistentemente, donde visionaba una corrida en la que se mezclaban toros de tamaño natural, toros a escala humana y toros gigantes.

La autora confiesa que hablaba mucho de aquel sueño de toros y decía: Quisiera hacer el toro como es. Un toro enorme, de tamaño natural. Pero también quisiera hacer la plaza. De tamaño natural. A escala humana. Pero ¿cómo hacerlo? ${ }^{3}$.Esta frase la pronuncia Picasso en el año 1958; por aquel tiempo ya había conocido al torero Luis Miguel Dominguín ${ }^{4}$, con quien solía conversar sobre el arte de la tauromaquia ${ }^{5}$. Sin embargo, será con la llegada a la Riviera francesa de su amigo Antonio Bonet, cuando se despierte el interés de Picasso por construir una plaza de toros. Bonet había conocido a Picasso cuando intervino en el pabellón de España en París en 1937, trabajando bajo las órdenes del arquitecto Josep Lluis Sert y mientras Picasso se encontraba realizando el Guernica ${ }^{6}$.

\section{Las ideas de Le Corbusier como ci- mientos teóricos de la construcción.}

El planteamiento del proyecto como plaza de toros moderna no solo es un conjunto arquitectónico y una puesta en valor de las teorías de la época, sino algo más, un experimento de arquitectura de masas. Por ello no podríamos abarcarlo en su justa dimensión, si no habláramos de la figura de Le Corbussier, maestro de Bonet, quien intelectualmente proporciona la visión de una arquitectura moderna de un foso público, en el ámbito de una arquitectura al servicio de la sociedad y su relación con el entorno natural. Esta es una antigua propuesta de Le Corbusier, es el reflejo de su proyecto de arquitectura en Argentina, espacio donde quería implantar sus famosas teorías sobre lo que en su publicación "Précisions sur un état présent de l'architecture et de l'urbanisme" describió como el horizontal insigne ${ }^{7}$. Por giros del destino Argentina será el lugar donde su discípulo Bonet realizará gran parte de su trayectoria profesional y pondrá en práctica parte de estas ideas.

El germen de la arquitectura que Bonet proyectará para crear la plaza de toros que Picasso deseaba, hay que buscarlo en la relación de Le Corbusier con este país y con toda Latinoamérica. El arquitecto franco suizo Charles Edouard Jeanneret, Le Corbusier, mantuvo con la Argentina una larga y fructífera relación, a veces 
también frustrante. Durante una década proyectó un conjunto de obras y acciones que había ideado con sus discípulos de Buenos Aires, aún antes de su primera visita en 1929, en medio del debate internacional sobre la renovación de la arquitectura y el urbanismo ${ }^{8}$. Conocido como uno de los arquitectos de la modernidad más importantes del siglo XX, Le Corbusier es además una figura icono de los intentos latinoamericanos por acercarse a los avances arquitectónicos de Europa y Estados Unidos.

En octubre de 1929, Le Corbusier realizó en Buenos Aires un ciclo de diez conferencias, invitado por la Asociación Amigos del Arte en la Facultad de Arquitectura Arte y Diseño (FAAD). Esta visita se extiende no solo a Argentina, sino también a Río de Janeiro, Asunción y Montevideo, lo que motivará en el arquitecto el conocimiento de una naturaleza primitiva y pura, el paisaje sin modificar y un espacio infinito, cuyos elementos el autor añoraba en Europa. Le Corbusier venía a difundir su ideario en conferencias, pero llevaba una visión romántica del paisaje humano alimentada en París por relatos de sus amigos y discípulos Ricardo Güiraldes y Alfredo González Garaño; pero se alarmó cuando pudo contemplar el ritmo desmesurado en que crecía Buenos Aires frente a la virginidad del territorio y, lo que podríamos llamar, la ausencia de miradas modernas sobre la planificación urbana.

En las conferencias que impartió valoraba la relación del arquitecto con el paisaje, defensa que su discípulo Bonet llevará a sus máximas consecuencias en sus experiencias arquitectónicas en La Solana del Mar, en Uruguay. De ahí que Bonet propondrá, a Dominguín y a Picasso, la ubicación de la plaza de toros proyectada no en el espacio urbano, tal y como era habitual en España, sino en un entorno abierto como la Casa de Campo, parque natural protegido y que sirve de pulmón a la metrópolis, como un todo de integración con la naturaleza y el entorno.

Le Corbusier, como autor de una arquitectura depurada, plasmó sus teorías sobre "Los cinco puntos de la nueva arquitectura" 9 , de cuyas aportaciones tomará la visión técnica y funcional de la arquitectura su discípulo Antonio Bonet. El maestro diseñó a lo largo de su vida numerosos edificios, pensados para albergar y circular mul- titud de personas, basados en la expresión de los materiales y los sistemas constructivos. A pesar de su enorme influencia, sus iniciativas en Argentina no se llevaron a efecto; sin embargo su obra teórica ha influido, en gran manera, sobre todo a sus seguidores y en la arquitectura americana en general en los últimos cincuenta años ${ }^{10}$.

En cuanto al planteamiento técnico del proyecto y su referente arquitectónico, la relación de Le Corbusier con el edificio taurino no existe. Sin embargo, Bonet tomará del maestro la experiencia que proyecta en su único coliseo público y que, hoy día, perdura. En realidad, es un conjunto de instalaciones relacionadas entre sí, el Estadio de Firminy-Vert, en Francia ${ }^{11}$. En este gran conjunto destacarán algunos aspectos, similares en intención, que serán utilizados por Bonet en el proyecto del coso: la integración de edificio en el espacio circundante, la utilización del terreno edificable en la ladera y la orientación de la construcción, tan importante en una plaza de toros, incluso en la escenificación de la fiesta. Firminy-Vert, esta orientado según el eje Norte-Sur con el fin de lograr la mayor iluminación posible y regular el sentido de la luz.

\section{Antonio Bonet y sus procedimientos arquitectónicos en la sociedad de masas.}

El creador del proyecto, Antonio Bonet Castellana, es hombre polifacético y emprendedor, además de un gran urbanista y diseñador industrial. Su obra se mueve entre dos mundos, la vieja Europa donde se forma y el nuevo continente donde pone en marcha las enseñanzas de su maestro y aboga por una arquitectura racionalista y respetuosa con el paisaje que la rodea. Su trayectoria profesional es un claro ejemplo de sus teorías sobre la evolución de la arquitectura hacia procedimientos arquitectónicos sometidos a una sociedad de masas, a la racionalización y función de la arquitectura en la ciudad moderna. A todo ello se une la fascinación que siente Bonet por el surrealismo aplicado a la arquitectura como forma escultórica ${ }^{12}$. A los 20 años participó en el fundamental CIAM IV del que surgirá la Carta de Atenas, decálogo de la arquitectura y donde conoce a Le Corbusier ${ }^{13}$. La relación con Le Corbusier se inicia en 1936, y durante dos años colaborará con el maestro. Estando en 
París, en 1937, es llamado para colaborar en la construcción del pabellón español de la República, obra de Sert y Lacasa. En su interior, Picasso realiza el Guernica y, por primera vez, se encuentran el artista y el arquitecto ${ }^{14}$.

La formación intelectual y el pensamiento crítico de Bonet tienen relación directa con su amistad con dos compañeros argentinos, Juan Kurchan y Jorge Ferrari Hardoy, quienes le convencen para que en 1938 viaje a Buenos Aires ${ }^{15}$. Allí permanecerá durante décadas, con algunas etapas de su vida, también, en Punta del Este en Uruguay y en España. Como cofundador del grupo Austral argentino, en junio de 1939, publicaron el manifiesto del Grupo bajo el título "Voluntad y Acción"16, en el que defendían la superposición de algunos valores del surrealismo a la formación racionalista de los arquitectos, e incorporaban las necesidades psicológicas del individuo al funcionalismo estricto del movimiento moderno. En definitiva, el Grupo Austral, proponía enriquecer la arquitectura racionalista con aspectos provenientes de la psicología, el paisajismo y las tradiciones locales. Este manifiesto expone la postura de Bonet frente a la arquitectura y su esfuerzo por establecer una continuidad con el paisaje, las técnicas y los materiales de cada zona. Esos años, además de realizar numerosos proyectos de planificación y obras a todas las escalas, también ensaya el tema de las bóvedas parabólicas en algunas casas planificadas.

Bonet, desde sus inicios, escribe sus reflexiones sobre la humanización de la arquitectura y su integración en el entorno, que serán reflejos de sus obras posteriores, afirmando que:

\begin{abstract}
... debemos plantear las bases esenciales para que la nueva vivienda integral haga posible que el hombre moderno recobre el suelo: su contacto con la tierra y la naturaleza, en fin la alegría de vivir, la libertad y el goce estético con el espectáculo de la arquitectura. Conseguiremos el milagro de los grandes espacios y la supresión de las grandes distancias y los inmensos suburbios ${ }^{17}$.
\end{abstract}

Sin duda, el texto recoge parte del optimismo del Grupo Austral dirigido a los arquitectos y sus problemas, en los que se vislumbra su fascinación por el paisaje como medio de integración arquitectónica. Bonet, nunca abandonará las líneas fundamentales de la obra de su maestro Le Corbusier, sobre todo cuando, en 1942, participa en la constitución de la Organización de la Vivienda Integral en la República Argentina, de cuyo organismo será secretario. Sus pensamientos irán plasmándose, poco a poco, en los diferentes proyectos que surgen a lo largo de toda su carrera, como en sus trabajos con OVRA, y así lo afirma cuando escribe:

En este proyecto, no existe ningún argumento seriamente atendible, ni aun la rutinaria servidumbre de concepción sometida a lo foráneo en que viven algunos argentinos ${ }^{18}$

A pesar de residir en Buenos Aires, en los años sesenta viajó frecuentemente a España y tuvo varios proyectos en Cataluña, diseñando varios conjuntos de viviendas y edificios públicos. El edificio más significativo de los realizados por el arquitecto, que se vincula con nuestro proyecto, es el Canódromo de Barcelona, finalizado en los mismos años que Bonet proyecta con Picasso la plaza de toros. Sus similitudes son, sobre todo, la utilización de elementos comunes que tomará como referencia posterior, como es su planta parabólica, los cerramientos de aluminio y grandes paneles de cristales móviles. El arquitecto se plantea la forma general del edificio como una solución estructural fuertemente condicionada por la presencia de los materiales que utiliza, de la misma manera que hará con el coso taurino. Estas formas que aparecen como elementos flotantes son el resultado de la utilización de la lámina parabólica de la cubierta, los brise-soleil en vertical y la distribución del conjunto de gradas con la terraza de la parte superior ${ }^{19}$. La utilización de líneas parabólicas, la disposición de las gradas, los materiales industriales como son los tirantes y el tratamiento lumínico, serán, de igual modo, los elementos que vuelva a utilizar en el anteproyecto de la plaza. El modelo del canódromo resume el carácter de su obra pública, hasta tal punto que su relevancia se consolidó cuando en 1963 obtuvo el premio FAD y, hoy día, es un edificio catalogado Bien de Interés Cultural.

En definitiva, Bonet, como autor, es considerado purista por su manera de entender e interpretar la arquitectura, cuyo objetivo es la construcción de líneas simples, donde la estructura no solo es visible sino que es el único elemento 
que configura el edificio, teniendo como material imprescindible el hormigón, al que considera la base de la arquitectura moderna. Su valor está en haber llevado la construcción de su tiempo a la humanización de las formas y las teorías racionalistas con una vigencia actualizada, al considerarla como integración total de las artes. De ahí la importancia que supuso para el arquitecto el proyecto de la plaza de toros que aunaba las teorías de su juventud, donde la pintura, formas y escultura fueran el motor de la nueva arquitectura integrada en el entorno natural. La teoría de Bonet sobre el tema describe su visión espléndidamente: La arquitectura de nuestra época sólo se logrará si consigue integrarse entre esos dos extremos: el orden de lo básico, general, colectivo, y la libertad máxima en el detalle, lo individual2o.

\section{Picasso y la tauromaquia.}

Sentados los precedentes del pensamiento arquitectónico que va a presidir el proyecto, hay que entender que la plaza de toros para Picasso va a ser un conjunto donde se unan intereses comunes. Por una parte, la modernización del espacio taurino, como arquitectura social; por otra, la posibilidad de un lienzo pétreo para abarcar todas las posibilidades de su arte, ya que tal y como veremos en las notas del autor, a pie del anteproyecto, los espacios decorados con relieves y cerámica son excepcionales. La necesidad de realizar esta plaza se une a la propia iniciativa del autor por encontrar un nuevo impulso de inspiración y, sobre todo, la oportunidad de plasmar los avances conseguidos de la técnica cerámica en los talleres de Mougins.

Como constante en su obra, se ha estudiado insistentemente su personal visión del arte de la tauromaquia. Un hecho común es que Picasso muestra el mismo interés por representar la lucha permanente entre el equilibrio natural de las cosas y la lucha por el control de las mismas. Para Picasso la fiesta es el reflejo de los instintos contradictorios, de lo racional del torero frente a lo irracional del animal, llevado, en ocasiones a percibir su preferencia por la pureza animal, frente al hombre ${ }^{21}$. La fascinación ancestral de Picasso por el toro procede, por una parte, tal y como afirma Antonio Saura, de una incompa- tibilidad semántica, a partir de un arte efímero y fugaz que se desarrolla vertiginosamente en el tiempo22; y, por otra, del descubrimiento de un nuevo material que trabajar: a Picasso el descubrimiento de un material tan dúctil como el barro le proporciona la posibilidad de expresar la tauromaquia. Será en los talleres de Vallauris donde se inicie con la realización de sus dos primeras obras, dos toros en 1946, y a continuación numerosas representaciones de la fiesta y del arte del toreo ${ }^{23}$. Si desde muy joven muestra su afición a los toros a través de dibujos y primeras pinturas, más tarde, tras plasmar el sentido de la fiesta, tal y como la sentía, abandonó los lenguajes estéticos preestablecidos por la mirada feroz hacia el drama de la existencia efímera que, además, se convierte en el paradigma de su obra. En la madurez final, su postura es más humanizada y menos dramática, y contempla la fiesta más como un rito que transmite paso a paso perfilando sus secuencias como instantáneas sensoriales.

La ilustración será uno de sus medios preferidos para expresar su afición por la fiesta. En 1928 había iniciado con Gustavo Gili i Roig, editor catalán, la realización de una edición sobre la "Tauromaquia o arte de torear de Pepe Illo" 24, para ser presentada en la Exposición Universal de Barcelona del siguiente año25. Aunque no pudo llevarse a cabo hasta años después, Picasso realizó siete aguafuertes y dibujos sobre el tema, que muestran, por entonces, la fuerza y la violencia brutal del drama entre el hombre a caballo y el toro. En 1957 había reiniciado otra fase, muy alejada conceptual y estilísticamente de la primera, tal vez influido por la vitalidad y el dinamismo que se respirada en el mundo taurino por entonces. En dichas fechas trabajaba en el librotratado "Toros y toreros". A pesar de que estaba prácticamente terminado, cuando Picasso y Dominguín se encuentran, el artista quiso que el torero participara con un texto sobre el arte del toreo. El libro se terminó en 1959 con un total de diecinueve grabados, acompañados por los comentarios de George Boudaille y el texto de Dominguín sobre el arte y la fiesta ${ }^{26}$. La relación personal entre Luis Miguel Dominguín y Pablo Picasso fue profunda y fructífera, Picasso buscaba en el arte del toreo de Dominguín la emoción y el estímulo que produce el juego de la vida y 
la muerte. Durante casi una década, la relación entre los dos personajes estuvo cargada de una gran actividad creativa y de mutua admiración ${ }^{27}$. De esta amistad surgen libros y numerosas y suculentas ideas sobre el arte y los toros, recogidas en obras picassianas ${ }^{28}$.

En 1958 Picasso, está a punto de cumplir ochenta años. Dos años antes había terminado el mural del edificio de la UNESCO en París con enormes dificultades, en el que el autor había representado La caída de ĺcaro como símbolo del renacer de los errores humanos y con referentes a obras clásicas. Incomprendida por la mayoría de los críticos de la comisión de la UNESCO, su obra es defendida, tan solo, por Le Corbusier, miembro de la misma, quien es capaz de reconocer en la labor de Picasso una obra maestra ${ }^{29}$. Hecho que nos aproxima a una mirada y pensamiento común entre los dos autores.

En agosto de ese año hubo una corrida en Arles, donde toreaba Luis Miguel Dominguín y a la que asistió Picasso ${ }^{30}$. En ese año, 1958, había comprado el viejo castillo de Vauvenargues, que nunca habitó con su familia pero reformó como estudio y donde pasaba largas temporadas solo. El diestro fue invitado a la villa California, lugar de residencia del artista y en esta primera estancia, Picasso y Dominguín ya discutieron a propósito de la posibilidad de construir en el castillo una plaza de toros permanente ${ }^{31}$ ya que, en ese momento, Picasso tenía instalada desde 1948 la plaza en Vallauris, una plaza portátil, cerca de la villa California, donde celebraba fiestas de toros, incruentas, que duraron hasta $1961^{32}$.

La idea no surge espontáneamente; por el contrario, viene de atrás. El autor tan solo pone en marcha la realidad de sus fantasías artísticas. Durante estos años, la permanente obsesión de Picasso es la aplicación de las dimensiones de un espacio a los toros y a los elementos que rodean la fiesta, entre ellos el coso donde se desarrolla. De hecho, podemos apreciar en algunos de sus dibujos y grabados de la época el esbozo en líneas del coso taurino que determina el espacio donde se realiza la faena. Es más, cuestiona este planteamiento con sus amigos: pues, ¿por qué se puede hacer el toro de tamaño humano? ¿Se puede hacer cuando se quiera, pero no la plaza? ${ }^{33}$.
Picasso se plantea por primera vez el espacio arquitectónico como medio artístico. De esta inquietud nace la posibilidad de construir una plaza de toros, entendida como obra de arte total que pudiera abarcar las proporciones naturales que él mismo se planteaba, como máxima expresión de su concepción artística. Al mismo tiempo, tiene próximos los referentes arquitectónicos clásicos de los anfiteatros romanos de grandes dimensiones para acoger a multitudes, Nimes y, sobre todo, Arlés, su lugar favorito ${ }^{34}$.

\section{El proyecto.}

\subsection{Precedentes de plazas de toros}

La verdadera creación de una plaza de toros se hace más realidad a partir de la intervención de un tercer personaje, el arquitecto Antonio Bonet Castellana, con quien se encuentra en las estancias veraniegas del arquitecto en el sur de Francia ${ }^{35}$. En uno de estos encuentros y coincidiendo con Dominguín, hablaron del proyecto, pues Picasso se había decidido a construir la plaza definitiva en el castillo de Vauvenargues y desmontar la plaza portátil de Vallauris. La obra supondría para el artista enfrentarse al control del espacio fuera de la superficie pictórica tradicional. El reencuentro dará, posteriormente, sus frutos en los planos de un anteproyecto, realizado por Bonet en su estudio de Buenos Aires y que le presenta en el verano de 1962.

A pesar de tener como referentes las plazas de toros españolas, Bonet idea un coso en consonancia con su trayectoria arquitectónica y con el sentido de la arquitectura de masas de su maestro Le Corbusier. En aquellos años se estaban modernizando y ampliando varias plazas de toros en España, aunque prácticamente ninguna podía considerarse modelo para el autor. La única que seguía la línea del racionalismo arquitectónico y se alejaba de la tradición neomudéjar del edificio, tal y como había establecido el modelo de la plaza de las Ventas, era la de Alcalá de Henares, reformada entre los años 1956-1958, y que indicaba, en cierto modo, el cambio que se estaba operando en el concepto de coso público en nuestro país ${ }^{36}$.

El resto de las plazas de toros se construirán en los años sesenta, como la de Bilbao o Burgos $^{37}$. Pero realmente, si queremos encontrar 
algún referente moderno al anteproyecto de Bonet, hay que buscarlo en las plazas de toros que se construyen en los años cincuenta en lberoamérica, sobre todo en México. Las teorías y enseñanzas de Le Corbusier van a dar sus frutos en el campo de la arquitectura de masas y en arquitectos de la talla de Mario Pani Darqui, quien continuará sus enseñanzas a través de sus obras. La plaza de toros de México, llamada "El Toreo", con el coso a modo de anfiteatro y la utilización de materiales de hormigón y materiales industriales, puede considerarse el precedente inmediato de este proyecto ${ }^{38}$.

Los dibujos preparatorios y los documentos conservados muestran que, a la hora de diseñar el edificio, el pensamiento arquitectónico de Bonet sigue la trayectoria marcada por su maestro y estaba en conjunción perfecta con el artista, tal y como afirma en estas palabras:

Los elementos arquitectónicos... estarán formados por una serie, poco numerosa, de estructuras sistematizadas. Esas estructuras, podrán llegar al máximo de su perfección estética, técnica y económica..., tal cual se ha hecho en las grandes arquitecturas del pasado ${ }^{39}$.

De igual modo, en las reflexiones del autor, aparecen el concepto de estructura simple en un edificio y elementos funcionales para acoger a grandes masas, cuando afirma

... pero no cabe duda de que una vez demostrado que los edificios modernos pueden desarrollarse en estructuras simples, cada vez más parecidas entre sí, se hará potente la importancia de este sistema. Esos edificios serán utilizados y acondicionados para los más diversos usos, sin envejecer con ello... ${ }^{40}$.

Lo que nos confirma que, auspiciado por los intereses de Dominguín y de Picasso, el arquitecto desarrolló un proyecto donde pudo, aunque sin consolidar, proponer su visión de la arquitectura moderna y funcional.

\subsection{Los dibujos preparatorios}

Inicialmente, esta plaza estaba pensada para ser realizada en un espacio pequeño, a la medida de lo humano, pero posteriormente, con el desarrollo del proyecto $y$, ante la magnitud de sus dimensiones, se plantearán la posibilidad de instalarla en otro lugar. La plaza va a ser diseñada como un antiguo circo romano, a imitación del de Arlés, al que el artista tendrá como referente (Fig.1), aunque el coso no plasma lo antiguo a la hora de concebirse el edificio, sino que aparece como una construcción moderna y ligera, excavado en tierra, con capacidad para treinta mil espectadores y en línea con el suelo. Los planos que realiza Bonet, son una conjunción de espacio mediterráneo, modernidad y funcionalidad que abarca la distribución de multitudes.

En el anteproyecto que Bonet realiza para Picasso el edificio se presenta como un cuerpo ligero de masas, con una sólida estructura de hormigón armado de bóveda invertida, sujeta por tirantes y cerrada con aletas móviles transparentes de poliéster, acompañada de funcionamiento eléctrico ${ }^{41}$. Los bocetos presentan las dudas que surgen sobre la forma circular o hexagonal de la misma y la posible regulación de la iluminación, incorporando la luz artificial.

El diseño definitivo se ajusta a las pretensiones de Picasso. No fue fácil llegar a él; por el contrario, en los dibujos previos, a mano alzada, se percibe una primera intención de crear la plaza a partir de los precedentes de los arquitectos

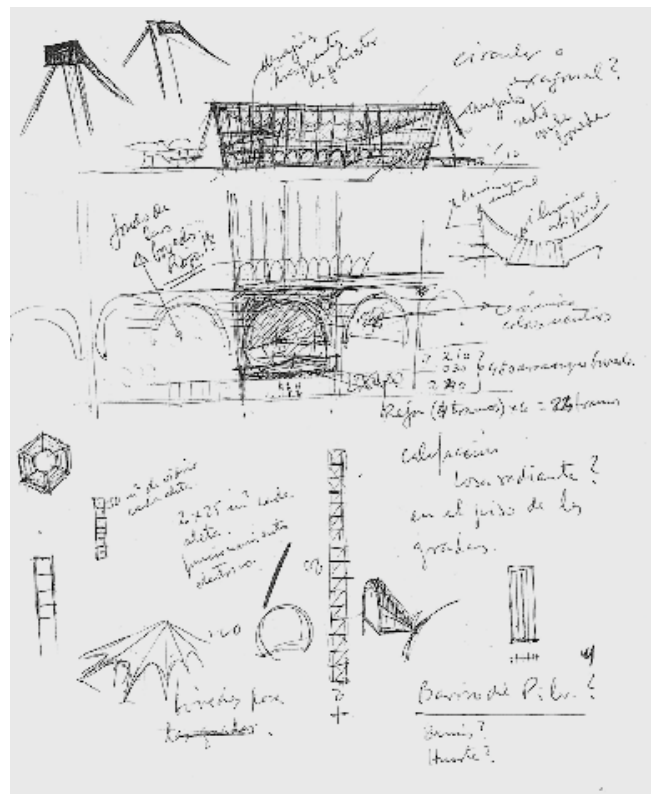

Fig.1. Modelo definitivo de plaza de toros con calefacción en losa radiante en las gradas. ACAC, (Archivo del Colegio de Arquitectos de Cataluña). Carpeta de Luis Miguel Dominguín. Barcelona, 1964. 

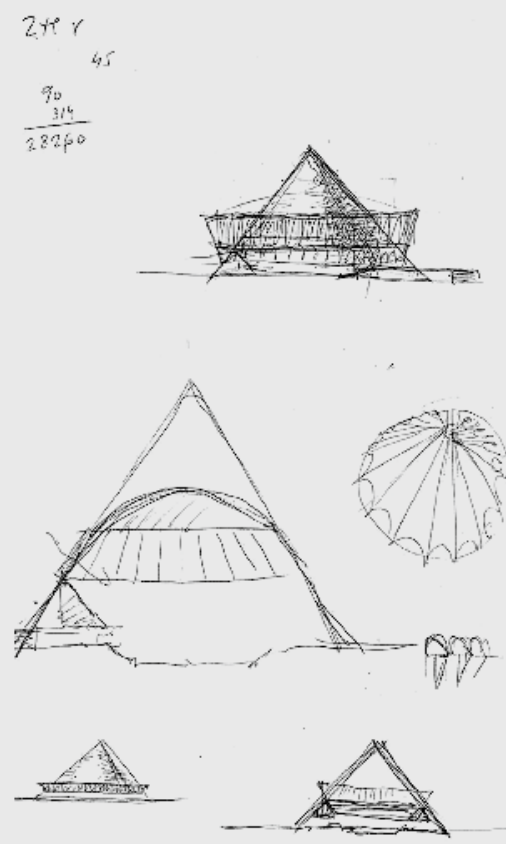

Fig. 2. Diseños de cubiertas de la plaza. ACAC, (Archivo del Colegio de Arquitectos de Cataluña). Carpeta de Luis Miguel Dominguín. Barcelona, 1964.

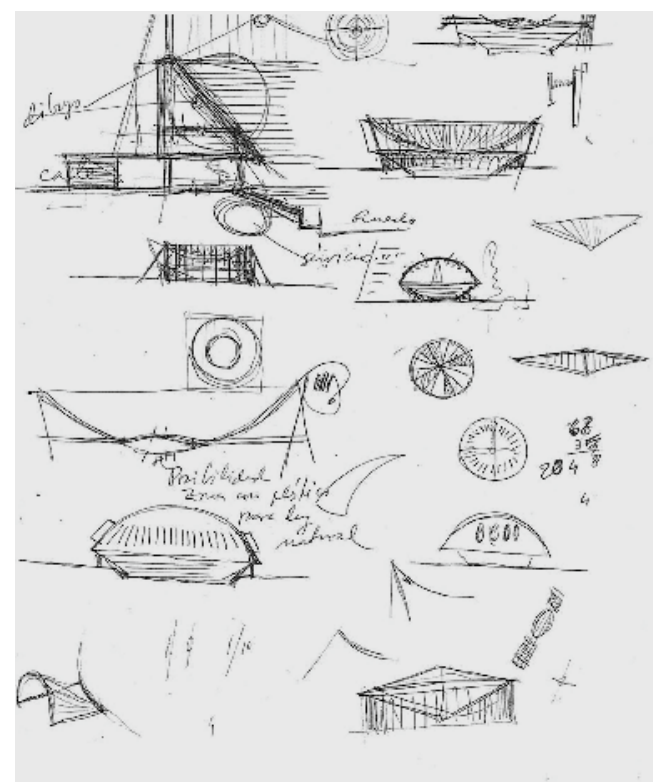

Fig. 3. Esbozos de cúpula plástica en la cubierta de la plaza. ACAC, (Archivo del Colegio de Arquitectos de Cataluña). Carpeta de Luis Miguel Dominguín. Barcelona, 1964. visionarios del siglo $\mathrm{XX}$, como son los modelos futuristas, pero con un concepto renovador del espacio, sobre todo del concepto de distribución de Le Corbusier. Los primeros bocetos se centran en la cubierta y muestran dos pirámides invertidas, inicialmente de manera sencilla. El problema se plantea con el resultado en el conjunto y su sistema de construcción (Fig.2).

La pretensión era encajar la cubierta en forma de cúpula de plástico transparente, sostenida por materiales de vidrio y de hierro. La utilización del plástico debía ser en forma de cuñas semiesféricas desmontables para aireación e iluminación natural. Este tipo de boceto tiene connotaciones similares a la arquitectura de líneas futuristas más modernas, como las ideadas por Oscar Niemeyer para la construcción de edificios públicos en los años cincuenta del pasado siglo ${ }^{42}$. La idea de una gran cúpula que cubra el coso se perfila desde el primer momento $y$, rápidamente, aparece la intención más funcional de una cubierta invertida con el consiguiente problema para sustentarla (Fig. 3).

El segundo modelo en los dibujos preparatorios era la incorporación de un cuerpo cilíndrico rompiendo el conjunto, con la parte superior de plástico, que pudiera levantarse en verano y

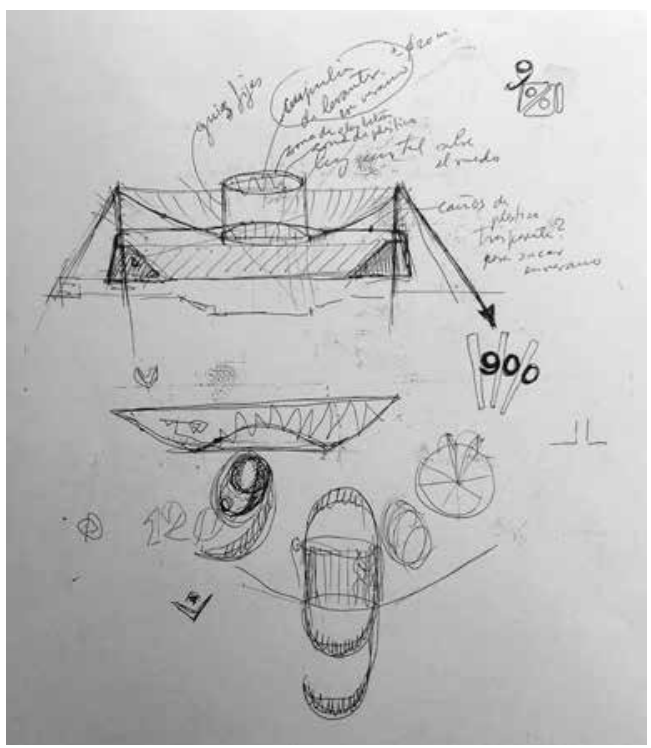

Fig. 4. Modelo de cubierta con cilindro insertado para controlar la luz. ACAC, (Archivo del Colegio de Arquitectos de Cataluña). Carpeta de Luis Miguel Dominguín. Barcelona, 1964. 


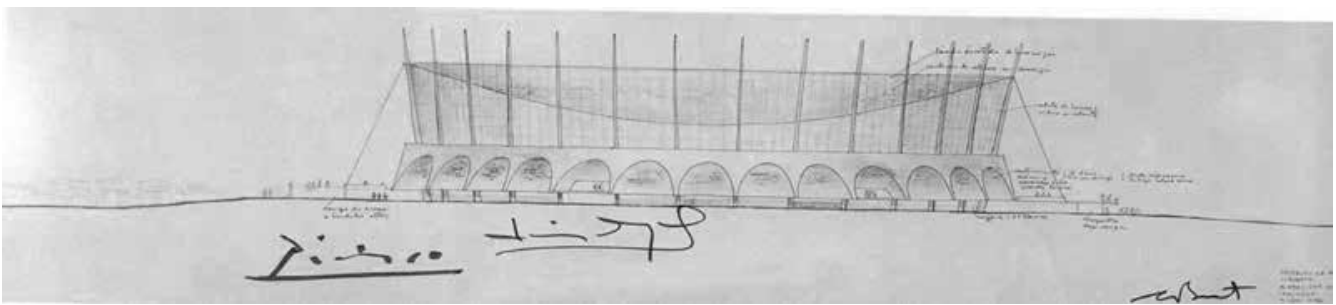

Fig. 5. Alzado del edificio. Anotaciones de la decoración cerámica de las bóvedas. ACAC, (Archivo del Colegio de Arquitectos de Cataluña). Carpeta de Luis Miguel Dominguín. Barcelona, 1964.

sostenido por guías fijas. Este modelo pretendía dar luz central sobre el ruedo ${ }^{43}$, a imitación de un foco gigantesco que concentrara la luz sobre el espacio de la faena taurina. La necesidad de diseñar un elemento duradero para cubrir el espacio de la plaza llevó al arquitecto a eliminar la propuesta para que la cubierta se realizara en plástico, tal y como aparece diseñada en los bocetos iniciales, en contraste con la masa maciza del coso (Fig. 4). Gracias a estos bocetos preparatorios que nos proporcionan numerosos datos, hasta ahora desconocidos, podemos desarrollar los pasos que se dieron hasta finalizar el proceso de la creación definitiva del coso (Fig. 5).

En el conjunto general, el autor tenía claro que la arquitectura debía someterse a los elementos picassianos, para ello tendría que inventar espacios para la gran decoración cerámica que el artista quería plasmar. De ahí la inversión de intereses porque Bonet, en parte, somete la arquitectura a las necesidades de las superficies decoradas y ello dará lugar al ritmo secuencial de las bóvedas parabólicas. Sobre los planos del arquitecto, Picasso anotó las precisiones oportunas y distribuyó la decoración cerámica tal y como la imaginaba (Fig. 6).

Bonet diseñará, para cubrir el coso, una gran bóveda invertida de hormigón. Esta bóveda será convexa, cubriendo la plaza en su totalidad, y estará reforzada por la sujeción de pivotes de hierro que tensarán las aletas de hierro y vidrio, dejando un espacio intermedio entre la cúpula y los soportes laterales que crea un efecto aéreo y más ligero. Un segundo elemento a tener en cuenta es la incorporación de un sistema de luz artificial en la bóveda que cubre el recinto, para propiciar la utilización del coso en espectáculos nocturnos. Otro de los aspectos estudiados es la importancia que adquiere la regulación de la iluminación natural de la plaza. Utiliza las aletas verticales, realizadas en vidrio, para manipular la luz interior, de tal manera que se estudia el control de la iluminación con su instalación rodeando todo el perímetro y regulando la luz para someterla a las necesidades de la lidia.

Para completar el conjunto, Antonio Bonet tomó como referente sus trabajos anteriores, especialmente el sistema de iluminación y aireación del Canódromo de Barcelona, cuya construcción nos proporciona la visión de los elementos que iba a aplicar en el planteamiento de la plaza de toros, como son la utilización de las placas de viroterm ${ }^{44}$ en el muro que funcionará como regulador térmico. De igual modo, en el conjunto de la construcción, el arquitecto volverá a tomar como modelo el mismo sistema para las bóvedas parabólicas (Fig. 7).

Los planos existentes muestran un edificio en alzado con tres partes perfectamente diferenciadas y al mismo tiempo integradas:

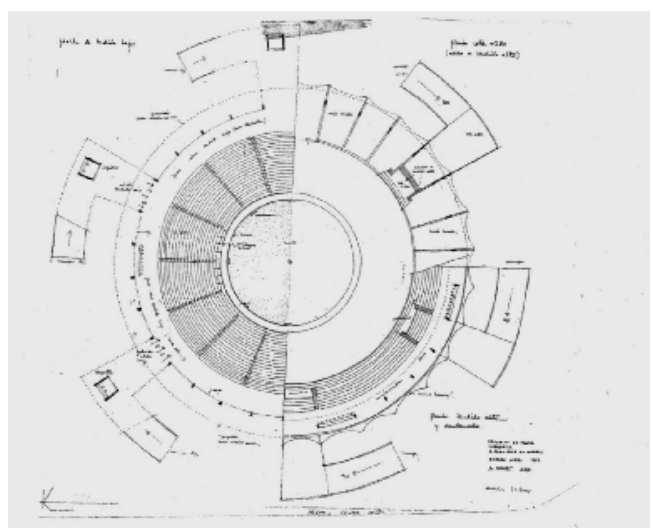

Fig. 6. Plano de la plaza, con distribución del gradería y acceso. ACAC, (Archivo del Colegio de Arquitectos de Cataluña). Carpeta de Luis Miguel Dominguín. Barcelona, 1964. 


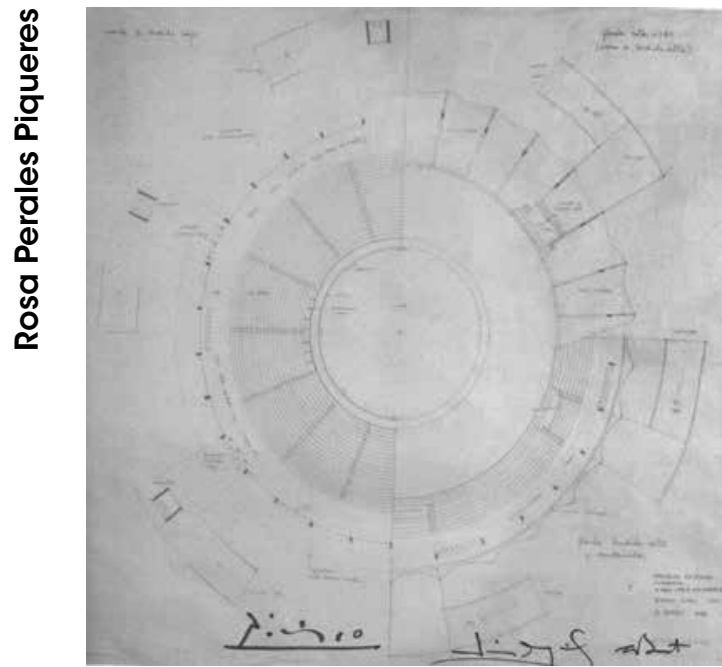

Fig.7. Plano definitivo del edificio firmado por Picasso, Luis Miguel Dominguín y Antonio Bonet. ACAC, (Archivo del Colegio de Arquitectos de Cataluña). Carpeta de Luis Miguel Dominguín. Barcelona, 1964.

el cuerpo superior de hierro y vidrio, el espacio medio con una estructura de graderío y un cuerpo inferior de hormigón, y el coso con accesos y espacios circundantes estudiados para ser integrados en un entorno natural. El efecto de integración de las partes se produce con la creación de tramos a modo de malla, en un total de veinticuatro y unidas por los pivotes de hierro, que armoniza y equilibra todas las masas arquitectónicas $^{45}$ (Fig. 8).

El cuerpo inferior del alzado se distribuye como una estructura a modo de secuencias de bóvedas cónicas, elevando el tendido superior del nivel del suelo y conectando con las rampas de acceso. Para reforzar el equilibrio de las bóvedas con el voladizo, Bonet quiso incorporar unos tirantes al exterior, que aparecen ampliando el espacio del edificio y abarcando el circundante. Un contorno exterior delimitaría el espacio arquitectónico a partir de la incorporación de 24 tramos de rejas y el círculo tendría un total de 140 metros de diámetro. (Fig. 9).

El interior de la plaza presenta espacios bien estudiados en cuanto a concentración de grandes multitudes y evacuación de las mismas. El coso tiene dos partes, una hundida, el tendido bajo, y una elevada, el tendido alto. La arena estaría bajo el nivel de la calle y las gradas elevadas sobre el suelo, situando los palcos por encima del burladero casi imperceptibles, pero simulados en el proyecto final. Es una plaza donde no se pretenden espacios diferenciados de público; es, en definitiva, una plaza popular, tal y como el maestro quería. A esta parte se le aplican las técnicas más novedosas del momento en cuanto a climatización, pues aparece la anotación en la que el tendido tendría calefacción radiante. La preocupación del arquitecto está en el equilibrio de la estructura. En el dibujo preparatorio se plantea las dimensiones del tendido superior y en función de él, las dimensiones de las bóvedas. Dependiendo de ello se necesitarían, para reforzar las estructuras, columnas ocultas como elementos sustentantes ${ }^{46}$ (Fig. 10).

El acceso se realiza por rampas en material de hormigón, tanto para el tendido superior

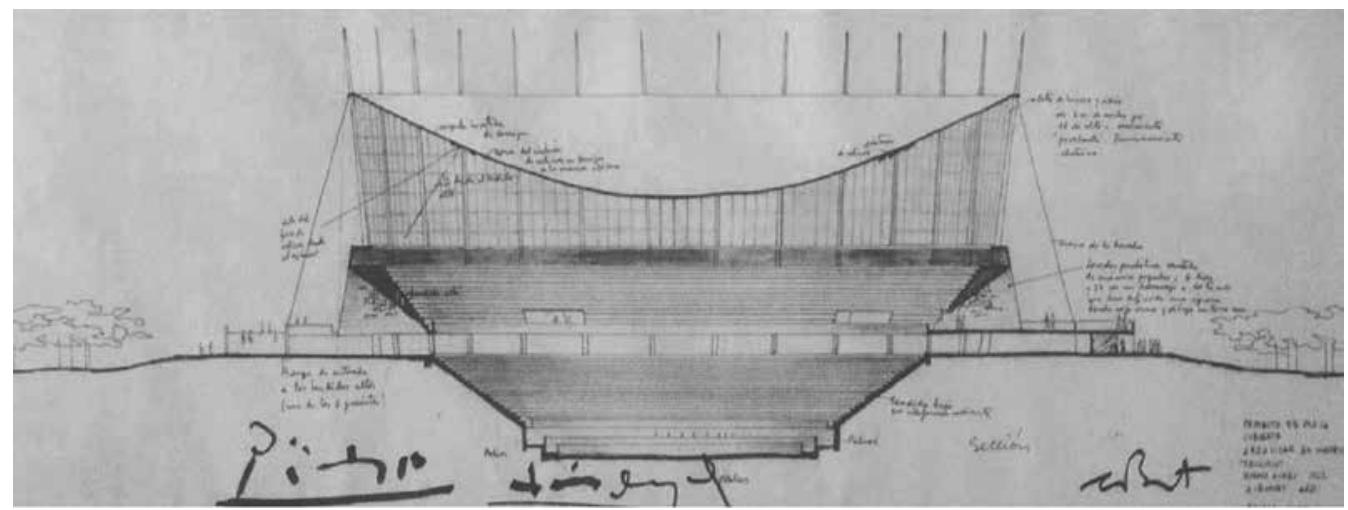

Fig. 8. Vista del graderío excavado en suelo, gradas superiores y rampas de acceso. ACAC, (Archivo del Colegio de Arquitectos de Cataluña). Carpeta de Luis Miguel Dominguín. Barcelona, 1964. 


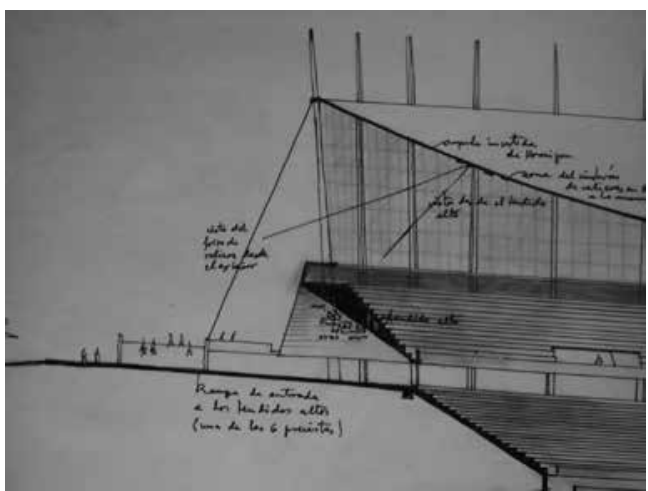

Fig. 9. Sistema de soportes de alzado, gradas y cubierta de cúpula invertida. ACAC, (Archivo del Colegio de Arquitectos de Cataluña). Carpeta de Luis Miguel Dominguín. Barcelona, 1964.

como para el bajo, del cual se distribuirían hacia el foso inferior. En dichos accesos, bajo las rampas, se disponen las taquillas de entradas al igual que el modelo de los estadios modernos, en un total de seis, y bajo el nivel de la calle quedarían a la altura del tendido bajo ${ }^{47}$. Las rampas están comunicadas por escaleras y plataformas metálicas al exterior. También Bonet pensó en el espacio circundante, de tal modo que diseñó aparcamientos de forma radial, con fácil acceso a las rampas. En ese espacio se incorporarían, posteriormente, las zonas de los toriles en estructuras ajenas al edificio principal. En la disposición de estos tramos, que equilibran el conjunto formado por partes diferenciadas, se aprecia la influencia del maestro Le Corbusier, así como en la planificación minuciosa de los espacios para la circulación de masas.

\subsection{La intervención de Picasso}

La decoración de la plaza está sometida a la idea del artista. Picasso elabora sobre el proyecto toda una temática basada en el concepto moderno de la cerámica y de los elementos pictóricos, sin olvidar la tradición del mundo mediterráneo. Para ello, escribe sus ideas sobre las copias de los planos y expone cómo distribuiría los motivos decorativos ${ }^{48}$ (Fig. 11). La bóveda invertida y de hormigón estaría decorada en su extremo con relieves a la manera clásica. El contorno del mismo tendría $225 \mathrm{~m}$. lineales en la superficie, a modo de cinturón. Su idea era realizar un relieve continuado alrededor de toda la plaza, y procu-

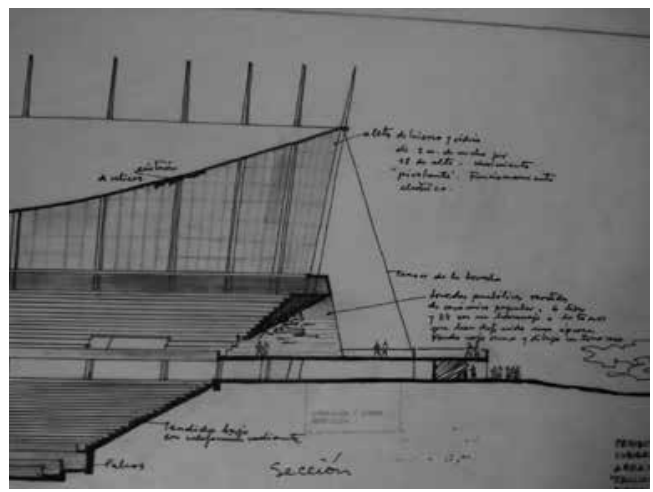

Fig. 10. Sección de alzado y gradas. Distribución espacial y taquillas. ACAC, (Archivo del Colegio de Arquitectos de Cataluña). Carpeta de Luis Miguel Dominguín. Barcelona, 1964.

rar que fuera contemplado desde el tendido alto y desde la calle. Queremos intuir que cuando Picasso se refiere a la manera clásica, está hablando de la interpretación de los distintos tiempos de la lidia en secuencias taurinas, tal y como realizara en sus series de Arlés en $1960^{49}$.

En las bóvedas parabólicas el artista había concebido un homenaje a los toreros de la historia, entre ellos a Pepe Illo, de quien era ferviente admirador. En los dibujos preparatorios Picasso

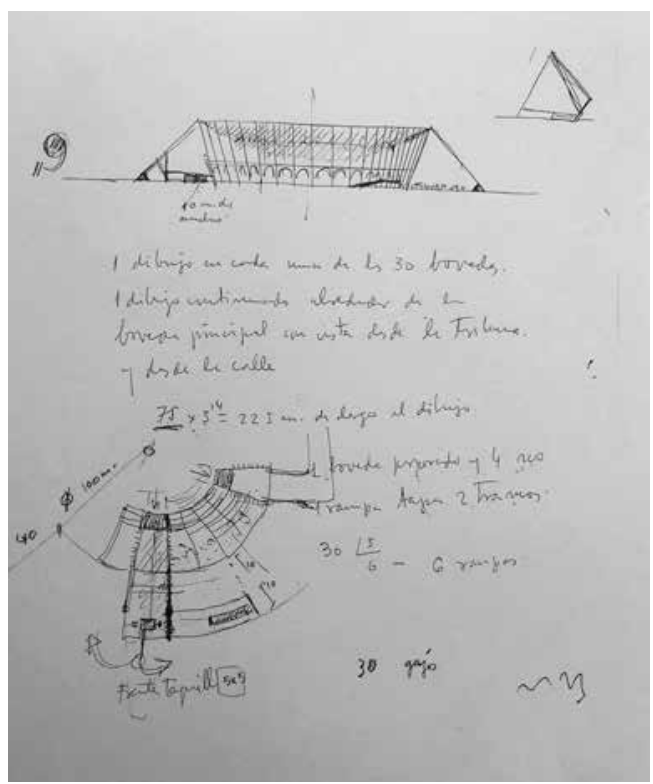

Fig. 11. Plano del coso de la plaza y desarrollo de la decoración cerámica. ACAC, (Archivo del Colegio de Arquitectos de Cataluña). Carpeta de Luis Miguel Dominguín. Barcelona, 1964. 
planifica un motivo decorativo en cada una de las treinta bóvedas, aunque luego decidirá dejar lisas las seis de acceso. Las bóvedas estarían decoradas en cerámica, tal y como describe Picasso, y de las cuales las seis de acceso serían decoradas de manera funciona ${ }^{50}$. El resto, hasta veinticuatro, tal y como hemos referido anteriormente estarían dedicadas a espacios cerámicos de homenaje a una selección de los toreros más relevantes de la lidia. Tan solo podemos hacernos una idea de las imágenes que el autor quería desarrollar, a partir de las cerámicas que en dicho momento y en otros soportes, como platos y vasijas estaba realizando. Es lícito pensar que la obra cerámica de tema taurino que Picasso realiza en los inicios de los años sesenta, tiene relación con su proyecto para decorar las grandes superficies que tenía previsto ejecutar en la plaza de toros, así como también nos aproxima a su posible temática la obra gráfica y de ilustración taurina que imprime por esos años ${ }^{51}$.

En las anotaciones a pie del anteproyecto concibe las cerámicas especificando que serán de carácter popular, y que serían realizadas en colores neutros, tal y como aparecen reseñadas en los bocetos iniciales; así mismo, determina que los fondos de las bóvedas serán en rojo, todo un muestrario simbólico del color vinculado al sacrificio taurino. Más tarde, en el proyecto definitivo, escribe que serán decoradas con fondo rojo oscuro y que los dibujos que se diseñarán debían ir en tonos secos; estos últimos corresponderían a las anotaciones, dedicadas a los que han definido una época. Picasso había realizado con anterioridad algunos grabados sobre linóleo en Vauvenargues, similares a los que quiere plasmar en la plaza y dentro de la misma gama de colores que propone ${ }^{52}$.

Los antecedentes más próximos a su propuesta podemos encontrarlos en la obra del artista en la década de los cuarenta. En 1946 Picasso se había dejado seducir por el arte cerámico que practicaba, desde entonces, en los talleres de Vallauris, y en los cuales había realizado gran parte de la cerámica de aquellos años. El barro será el soporte ideal para numerosas series de platos, jarras y nuevas formas como azulejos, vasijas o cuencos, cuya temática habitual será la tauromaquia ${ }^{53}$. El artista practica en los platos las secuencias de la lidia en la plaza y refleja el interior de esta en instantáneas con el público. El torero realiza la faena con singulares perspectivas y con gran elegancia, a la manera en que se muestran las imágenes de la fiesta reglada ${ }^{54}$. En estos años, Picasso ya ha desarrollado una gran técnica cerámica y su intención de decorar el proyecto de la plaza de toros tiene su sentido. Sobre todo porque, como podemos observar en los distintos apuntes a pie de plano, el artista distribuye las series cerámicas según un plan preestablecido que va desde el clasicismo de la parte superior a los referentes históricos de la parte inferior. Dicho plan se inicia con relieves clásicos sobre mitos legendarios en donde intervendrán escenas que desarrollen, secuencialmente, la tauromaquia y finalizarán en las bóvedas parabólicas inferiores con las faenas más destacadas de los maestros modernos de la historia taurina.

Como ceramista Picasso se abre a una extraordinaria plástica, en la que ejerce más como decorador que como formalista, ya que no mezclaba las materias como los óxidos, ni las tierras, ni tampoco se preocupaba de la labor fundamental del ceramista, la cocción ${ }^{55}$. Digamos que su faceta de pintor vuelve a superponerse sobre el soporte que utiliza, elevando esta disciplina a los niveles más altos de la expresión plástica. Su inspiración procede de la cerámica tradicional española y provenzal, destacando el gran colorido de la de Manises, muy extendida en España. El tipo de cerámicas que el artista pretendía aplicar a la decoración del exterior, en los huecos o conos dedicados a las figuras del toreo, iba a ser realizada en los talleres de Vallauris. No podemos olvidar que el maestro, hacía poco tiempo, había finalizado el gigantesco mural de la UNESCO y que la técnica utilizada en dicho mural, posiblemente, le serviría como referente para realizarla posteriormente, en la plaza.

\section{4 . El emplazamiento de la plaza de toros}

El torero Luis Miguel Dominguín, entusiasmado por la idea de una plaza de toros cubierta, dijo a Picasso que era una plaza digna de Madrid, ya que la última, construida no hacía mucho, mostraba las tendencias historicistas tradicionales ${ }^{56} \mathrm{y}$ no estaba a la altura de la que planteaba Bonet. El moderno proyecto y de extraordinaria nove- 
dad, sería todo un hito en la historia del toreo. Dominguín presentó el mismo a Franco y durante dos años se movilizó para que miembros de la alta burguesía madrileña, próxima al régimen, facilitaran su construcción. Hasta tal punto que se barajaron varias posibilidades de ubicación, como el barrio del Pilar ${ }^{57}$, la Casa de Campo, o las afueras de Madrid, lo cual nos hace pensar que, en un principio, las gestiones realizadas iban por buen camino ante el dictador. Se desarrollaron varios intentos para implicar a sectores sociales y al mundo empresarial, y conocemos que algunos de ellos, como el empresario Enrique Fernández de Soto, presentó al torero un presupuesto para ubicar la plaza en unos terrenos en la carretera de la Coruña, denominados Cuesta de las Perdices, en el kilómetro ocho de Madrid. El terreno tenía una superficie de 350 hectáreas y fácil acceso desde la carretera. Su precio era de catorce millones y medio de pesetas ${ }^{58}$. La segunda opción es la petición de un presupuesto general para construir la plaza en la Casa de Campo a la empresa ERG, que eleva el gasto de construcción a setenta y cuatro millones de pesetas en Enero de $1964^{59}$. A pesar de todos estos esfuerzos en los que intervienen las constructoras, empresarios y aficionados privados, la iniciativa se paraliza porque Franco no dará su aprobación al proyecto. La razón no será otra que la enorme aversión del dictador a que Picasso tenga que desplazarse a España e intervenga en la plaza con su gran obra cerámica, de modo que un proyecto revolucionario y de grandes proporciones para la arquitectura taurina moderna no podrá desarrollarse por motivos meramente políticos.

A finales de 1964, Picasso trabajará en otros proyectos que desvían la atención de su sueño en utilizar el edificio de una plaza de toros como lienzo pictórico y, sobre todo, en realizar una obra que supusiera un homenaje al arte taurino. Hubiera supuesto el último gran reto del artista, al mismo tiempo que el novedoso proyecto de reformar la arquitectura taurina, pero el proyecto cayó en el olvido. Bonet continuó trabajando en Cataluña, donde creará grandes conjuntos de edificaciones y aplicando sus teorías de arquitectura de formas integradas en el paisaje ${ }^{60}$.

El estudio de este proyecto viene a contradecir las afirmaciones que Santiago Amón realiza en el año 1989, en su libro sobre Picasso, donde afirmaba que ... Hay, sin embargo una manifestación estética que, debiendo tanto al arte de Picasso, no halló en él un eco personal equivalente, ni siquiera relativo: la arquitectura ${ }^{61}$. Amón insinúa que no quiere decir que el artista tuviera la obligación de proyectar o de construir, pero sí que a tenor de los supuestos picassianos, se abrieron nuevas sendas expresivas en la arquitectura que no fueron utilizadas por él. Según el autor, el cubismo es la aportación de Picasso al proyecto arquitectónico moderno y al experimento de la ciudad contemporánea. Es más, afirma que ... de la nueva visión del cubismo surge la moderna concepción arquitectónica, como es el caso de Le Corbusier, como gran impulsor ${ }^{62}$.

\section{Conclusión.}

Como conclusión y tras el fracaso de esta iniciativa, que hubiera modernizado la imagen de las plazas de toros en España, la singularidad de este proyecto reside en coincidir con un tipo de arquitectura pública avanzada, que aunaba las grandes construcciones realizadas en los años cincuenta bajo la línea de la arquitectura de Le Corbusier y un proyecto arquitectónico de integración en el medio natural. El proyecto, que no pudo realizarse, es el único intento, conocido hasta el momento, de Picasso por aproximarse a la arquitectura como superficie pictórica de grandes dimensiones y con un concepto amplio para la contemplación de su obra por grandes multitudes. De tal manera que la intención del autor se revela como un precedente de lo que hoy día será una de las máximas del arte contemporáneo, es decir la ejecución de obras e instalaciones en amplias superficies para ser contemplados por una gran masa de público. Bonet sirvió de enlace entre las ideas de Le Corbusier y la fantasía de Picasso, aunque diluyéndose en el tiempo todo el esfuerzo del octogenario artista ${ }^{63}$. Los dos tenían una visión moderna del futuro del arte en todas sus dimensiones y su percepción de la misma va más allá de la mera conexión generacional. Fueron capaces de crear una imagen única a través del cubismo como forma de expresión, tanto arquitectónica como pictórica, conseguida a partir de la fragmentación de las formas, y, en su proyección, de concebir la creación de un arte total. 


\section{NOTAS}

1 A. D. Olano, Picasso íntimo, Editorial Dagur, Madrid, 1971, p.83.

${ }^{2}$ H. Parmelín, Picasso en el ruedo, Editorial Plaza y Janés, S.A., Barcelona, 1961, p.56.

${ }^{3}$ H. Parmelín, Ob. Cit., Barcelona, 1961, p. 168.

${ }^{4}$ P. Cabanne, El siglo de Picasso, Gloria y Soledad, Ministerio de Cultura, Madrid, 1983, T.4, p. 7 . El autor afirma que Picasso y Dominguín se encuentran por primera vez en la plaza de toros de Nimes en 1952.

5 A.D. Olano, Ob. Cit, Madrid, 1971, p.43.

${ }^{6}$ F. Álvarez-J. Roig, Bonet, Ministerio de Fomento, Colegi d'Arquitectes de Catalunya, Barcelona, 1996. J. RoigF. Álvarez, Antonio Bonet Castellana, Clásicos del diseño, $n^{\circ}$ 6". Santa \& Cole Ediciones de Diseño, S.A., Centre d'Estudis de Disseny (CED) y Edicions UPC, 1999.

${ }^{7}$ C.E. Jeanneret, "Precisións sur un état de l'architecture et de l'urbanisme", en Le Corbusier en Buenos Aires, 1929. Primera conferencia en Amigos del Arte, 3 de Octubre, 1929, Buenos Aires, Sociedad Central de Arquitectos, 1979, en p. 19; p. 21 p. 52.

8 J. F. Liernur - P. Pschepiurca, "La red austral. Obras y proyectos de Le Corbusier y sus discípulos en la Argentina (1924-1965)", en Colección Las ciudades y las ideas, Bernal- Universidad Nacional de Quilmes, 2008, Capítulo XIII.

${ }^{9}$ L. Benévolo, Historia de la Arquitectura Moderna, Editorial Gustavo Gili, $8^{a}$ edición, Barcelona, 2010, p. 34-36.

10 Conocemos en México a su seguidor Mario Pani Darqui, en Brasil Oscar Niemeyer, en Argentina, a los anteriormente citados, Antonio Bonet Castellana, Juan Kurchan, Jorge Ferrari Hardoy, Amancio Williams. En Uruguay, el teórico urbanista Carlos Gómez Gavazzo, y, en España, Francisco Javier Sáenz de Oiza.

${ }^{11}$ El estadio Firminy fue construido entre 1966 y 1968 según los planos de Le Corbusier. Tras el fallecimiento del arquitecto en 1965, la continuidad del proyecto quedó en manos de dos de sus colaboradores: André Wogenscky y
Fernand Gardien. La tribuna tiene una capacidad media de 4.180 plazas, con 500 cubiertas con un tejadillo que hubiera debido cubrir el conjunto de las gradas. Este edificio, construido según el programa inicial, fue declarado Monumento Histórico en 1984. Con anterioridad, le Corbusier había diseñado otros dos, sin realizar, el Cardinet de 1926 y el Pavillon Bat'a de 1936, los dos en París. G. Ragot, Le Corbusier à Firminy Vert, Manifeste pour un urbanisme moderne, Èditions du patrimoine, Centre des monuments nacinaux. París, 2011

12 F. Álvarez-J. Roig, Ob.. cit., Barcelona, 1996, p.16.

${ }^{13}$ F. Álvarez-J. Roig, Ob.cit., BarceIona, 1996, p.11.

${ }^{14}$ En estas fechas Bonet colabora en el montaje de las obras en el pabellón español y de la instalación de la fuente de Alexander Calder. F. ÁlvarezJ. Roig, Ob.cit., Barcelona, 1996, p. 12.

${ }^{15}$ E. Katzenstein, Antonio Bonet: Arquitectura y Urbanismo en el Río de la Plata y España, Espacio Editora, Buenos Aires, 1985.

16 Voluntad y Acción, Manifiesto del Grupo Austral. Bonet, Ferrari Hardoy y Kurchan, Junio de 1939, en la separata de la revista Nuestra Arquitectura, Junio, 1939. Portal de Arquitectura, Urbanismo, Arte y Diseño. Marcelo Gardinetti, [Consulta 02/12/2013] htpp:www.tecnne.com.

${ }^{17}$ A. Bonet Castellana, , "Estudio de los Problemas Contemporáneos para la organización de la vivienda integral en la República Argentina", en Cuaderno, $N^{\circ} 1$, OVRA, Buenos Aries, 1939.

A. Bonet Castellana, Ob. cit., 1939. 1939.

18 A. Bonet Castellana, Ob. cit.,

${ }^{19}$ F. Álvarez-J. Roig, Ob. Cit. . Barcelona, 1996, p. 166.

${ }^{20}$ Antonio Bonet Castellana, "Nuevas precisiones sobre arquitectura y urbanismo", en F. Álvarez-J. Roig, Bonet Castellana, Barcelona: Santa \& Cole Ediciones de Diseño " Centre de Estudis de Disseny y Edicions, UPC, 1999, pp. 213-221.

21 "a través de sus raíces españolas al final de su vida, acabó identificán- dose con el Mediterráneo, encarando el mito de la fuerza vital y taumárgica del arte.." A. Bonet Correa, Picasso en Madrid, Ministerio de Cultura, Museo Español de Arte Contemporáneo, Madrid,1978. pp. 23-24.

22 A. Saura, "Picasso y el Toro", ABC. Cultural, 7 de Enero de 1999.

${ }^{23}$ G. Ramié, Cerámica de Picasso, Editorial Poligrafa, S.A., Madrid. 1984, p.18.

${ }^{24}$ En 1959, Picasso realizó una tirada limitada y numerada de 26 ejemplares, (28 en ediciones especiales) sobre "Tauromaquia o arte de Torear, por José Delgado, alias Pepe-Hillo", publicadas por Ediciones La Cometa de la Editorial Gustavo Gili, S.A. de Barcelona. Fueron realizadas en el taller Lacourière de París, bajo la dirección de $\mathrm{M}$. Jacques Frélut. G. Bloch, Pablo Picasso, catalogue de loeuvre gravé et litographié, T.I, Editores Koenfeld et Klisptein, Berna, 1968- 1979, T I, pp. 950-978.

${ }^{25}$ El libro pretendía presentarse en la Exposición Universal de Barcelona en 1929. El prólogo fué realizado por el escritor francés Henry de Montherlant, especialista en temas hispanos y muy entendido en el tema taurino. Este texto se conservó y fue editado en el libro de "La España sagrada", de 1951. También referenciado en $\mathrm{H}$. de Montherlant, "Coup de soleil", NRF, París, 1976. G. Bloch, Ob. cit., Berna, 1968-1979, pp. 950-978.

${ }^{26}$ P. Picasso, L.M. Dominguín y G. Boudaille, Toros y Toreros, Le Cercle d’Art, París, 1961. Troisième édition, 1993.

27 P.J. Rico de la Casa, "Picasso, Luis Miguel Dominguín y Lucía Bosé: un inmenso territorio de amistad, complicidad y seducción mutua. Ejercicios de triangulación en los indeterminados espacios del arte, la sensibilidad y la belleza". En Picasso y Dominguín. Arte y Amistad, narrada por Lucía Bosé. Edita Museo del Tabaco, Principat d'Andorra, 2002, pp.23-29, pp.72-78.

28 R. Perales Piqueres, Picasso homenagen ao toureiro, Fundación Azpard-Szenes Vieira da Silva, Lisboa, 2000, pp. 6-10.

${ }^{29}$ P. O'Brian. Picasso, A Biography, Harper Collins, U.K, 2012, cap.20, p. 390. 
${ }^{30} \mathrm{H}$. Parmelín, Ob. cit. , Barcelona, 1968. p. 185. "....se le ve entrar y acodarse en la barrera. Luis Miguel Dominguín brinda su toro a Picasso. Le dedica un discurso en el que le habla de pintura. ...se miran a los ojos todo el tiempo que dura el homenaje de Dominguín. Picasso está de pie, con el sombrero en la mano. Picasso, se sienta con la montera de Dominguín en las manos..."

31 P. Cabanne, Ob. cit., Madrid, 1982,t-IV. pp.46-50.

32 G. Ramiè, Ob. cit., Madrid, 1984, p.170. "Entonces se asistía a un simulacro de corrida con la apariencia de una capea de pueblo, para mayor gozo de Picasso que, como es lógico, estaba en la presidencia. Novillos jóvenes eran lidiados tanto por los toreros invitados como por los caballeros en plaza que lo hacían a la portuguesa, pero con rejón inofensivo".

${ }_{33} \mathrm{H}$. Parmelín, Ob. cit. Barcelona,1968, pp. 168-169.

${ }^{34}$ A. D. Olano, Ob. ci t., Madrid, 1971, p. 83.

${ }^{35}$ R. Perales Piqueres, Ob. cit., Lisboa, 2000, pp. 6-7.

36 J.M. Cossío, Nuevas Plazas de Toros en España, El Cossío, T. IV, Espasa Calpe, S.A, Madrid, (1961) Edición 1999, p. 315.

37 J.J. Bonifaz, El Cossío, Los toros, tratado técnico e histórico. Nuevas Plazas de Toros, T. V, Espasa Calpe, S.A, Madrid, (1960-1964), Edición 1999, p.424-439.

J.J. Bonifaz, Ob. cit., Madrid, 1999, p.427.

38 J.J. Bonifaz, Ob. cit., Madrid, 1999, p. 427.

${ }^{39}$ F. Álvarez-J. Roig, Ob, cit, BarceIona, 1999, pp. 213-221.

${ }^{40}$ F. Álvarez-J. Roig, Ob, cit., BarceIona, 1999, pp. 213-221.

${ }^{41}$ ACAC, (Archivo del Colegio de Arquitectos de Cataluña), Carpeta Luis Miguel Dominguín, Barcelona, 1964. Las medidas serían, $2 \times 2,5 \mathrm{~m} 2$, cada aleta con funcionamiento eléctrico. En total 4,5 m2 de vidrio cada aleta.

${ }^{42}$ Como es el caso del Museo Nacional Honestino Guimarães de Brasil, diseñado por Oscar Niemeyer en los años cincuenta y finalizado en 2009. En Boletín Arquitectura en Concreto, $\mathrm{n}^{\circ}$ 6, 2012, [Consulta 04/12/2013] http:www.asocreto.org.co/boletín/boletín_arquitectura6.2012.php.

${ }^{43}$ ACAC, (Archivo del Colegio de Arquitectos de Cataluña), Carpeta Luis Miguel Dominguín, Barcelona, 1964. En el boceto preparatorio, describe un sistema de tirantes o "caños de plástico transparente para sacar en verano"... en R. Perales Piqueres, Catálogo de Picasso, homenagem ao toreiro, Fundación Aspard-Szenes Vieira da Silva, Lisboa, 2000, pp 8-10.

${ }^{44} \mathrm{El}$ viroterm es un sistema de aislamiento térmico, realizado en virutas de madera prensada con una pasta de cemento de varios grosores.

${ }^{45}$ ACAC, (Archivo del Colegio de Arquitectos de Cataluña), Carpeta Luis Miguel Dominguín, Barcelona, 1964. Estos pivotes de hierro sostenían paramentos realizados en vidrio.

${ }^{46}$ ACAC, (Archivo del Colegio de Arquitectos de Cataluña), Carpeta Luis Miguel Dominguín, Barcelona, 1964. La calefacción radiante estaría situada en el friso de las gradas.

${ }^{47}$ ACAC, (Archivo del Colegio de Arquitectos de Cataluña). Carpeta Luis Miguel Dominguín, Barcelona, 1964. Las taquillas tendrían unas dimensiones de $5 \mathrm{~m} \times 5 \mathrm{~m}$.

${ }^{48}$ ACAC, (Archivo del Colegio de Arquitectos de Cataluña). Carpeta Luis Miguel Dominguín, Barcelona, 1964. Estas anotaciones también aparecen en los dibujos preparatorios.

${ }^{49}$ C. Zervos, Pablo Picasso, 18891973, Catalogue raisonné, Editions Cahiers d'Arts París, 1957-1978, Vol. XIX, .pp. 227-252.

${ }^{50}$ ACAC, (Archivo del Colegio de Arquitectos de Cataluña), Carpeta Luis Miguel Dominguín, Barcelona, 1964. Las medidas en los bocetos preparatorios son de $4,80 \mathrm{~m}$ de altura en el arranque de la bóveda y 2,40 de ancho.

51 V.AA, Picasso. Libros Ilustrados, Colección de la Fundación Pablo Ruiz Picasso (1988-2008), Málaga, Edita Fundación Pablo Ruiz Picasso, 2008, pp.75-77, p. 262.
52 V.AA, Picasso. Obra Gráfica, Colección de la Fundación Pablo Ruiz Picasso (1988-2007), Edita Fundación Pablo Ruiz Picasso, Malaga, 2010, pp. 214-217.

53 N. Seseña, Picasso Ceramista, Fundación Pablo Ruíz Picasso, Málaga, 1990.

${ }^{54}$ A. Martínez Novallo, Los toros en las artes plásticas, El Cossío, T. VII, Espasa Calpe, S.A, Madrid, (1961) Edición 1999, p. 339.

${ }^{55}$ La cerámica como forma artística le lleva a encontrar un lenguaje popular a sus ansias de mostrar sus extraordinarias reservas creadoras unido a su ideario político. No hay que olvidar que por estas fechas se vincula al Partido Comunista Francés. A este respecto, la obra cerámica de Picasso nunca llegó a ser popular y fue exhibida como piezas excepcionales en los museos. G. Ramié, Ob. Cit., Barcelona, 1984.

56 J.J. Bonifaz, Nuevas Plazas de Toros, J.M. Cossío, T. V. Espasa Calpe, S. A., Madrid, (1961), Edición 1999, pp. 431-438.

57 Tal y como aparece nombrado con interrogante en el boceto $n^{\circ} 4$, en ACAC, (Archivo del Colegio de Arquitectos de Cataluña). Carpeta Luis Miguel Dominguín. Barcelona, 1964.

${ }^{58}$ ACAC. Ob. cit. Año 1964.

${ }^{59}$ ACAC. Ob. cit. Año 1964.

${ }^{60}$ F. Álvarez-J. Roig, Ob. cit. , Barcelona, 1996, p. 128 y pp. 156-224.

${ }^{61}$ S. Amón, Picasso, Editorial Visor, Madrid, 1989, p. 233.

62 S. Amón, Ob. cit., Madrid, 1989, p. 50.

${ }^{63}$ Ha habido intentos para la construcción del proyecto. En el año 2006 el Ayuntamiento de Málaga, la ciudad natal de Picasso, tuvo intenciones de construir la plaza, tal y como estaba diseñada en el proyecto original de los tres autores; su construcción correría a cargo del arquitecto José Manuel García. Arq.com.mx.Arquitectura.com. [Consulta4/12/2013] http://noticias. arq.com.mx/Detalles/8739.html\#. UqBpcid30dU. 